OPEN ACCESS

Edited by:

Gregory Franklin

Institute of Plant Genetics, Polish

Academy of Sciences, Poland

Reviewed by:

Anton R. Schäffner,

Helmholtz Zentrum München,

Germany

Zhi-Yuan Chen,

Louisiana State University, USA

*Correspondence:

Laura Jaakola

laura.jaakola@uit.no

${ }^{+}$Present address:

Emese Derzsó,

Plant Developmental Biology and Plant Physiology, University

of Kiel, Kiel, Germany

Specialty section:

This article was submitted to

Plant Metabolism

and Chemodiversity,

a section of the journal

Frontiers in Plant Science

Received: 14 February 2016

Accepted: 04 April 2016

Published: 21 April 2016

Citation:

Karppinen K, Derzsó E, Jaakola L and Hohtola A (2016) Molecular

Cloning and Expression Analysis of hyp-1 Type PR-10 Family Genes

in Hypericum perforatum.

Front. Plant Sci. 7:526.

doi: 10.3389/fpls.2016.00526

\section{Molecular Cloning and Expression Analysis of hyp-1 Type PR-10 Family Genes in Hypericum perforatum}

\author{
Katja Karppinen ${ }^{1}$, Emese Derzsó ${ }^{1+}$, Laura Jaakola ${ }^{2,3 *}$ and Anja Hohtola1 \\ ${ }^{1}$ Genetics and Physiology Unit, University of Oulu, Oulu, Finland, ${ }^{2}$ Climate laboratory Holt, Department of Arctic and Marine \\ Biology, UiT the Arctic University of Norway, Tromsø, Norway, ${ }^{3}$ NIBIO, Norwegian Institute of Bioeconomy Research, Ås, \\ Norway
}

Hypericum perforatum $\mathrm{L}$. is an important medicinal plant for the treatment of depression. The plant contains bioactive hypericins that accumulate in dark glands present especially in reproductive parts of the plant. In this study, pathogenesis-related class 10 (PR-10) family genes were identified in $H$. perforatum, including three previously unidentified members with sequence homology to hyp-1, a phenolic coupling protein that has earlier been suggested to participate in biosynthesis and binding/transportation of hypericin. The PR-10 genes showed constitutive but variable expression patterns in different $H$. perforatum tissues. They were all expressed at relatively high levels in leaves, variably in roots and low levels in stem and reproductive parts of the plant with no specific association with dark glands. The gene expression was up-regulated in leaves after salicylic acid, abscisic acid and wounding treatments but with variable levels. To study exact location of the gene expression, in situ hybridization of hyp-1 transcripts was performed and the accumulation of the Hyp-1 protein was examined in various tissues. The presence of Hyp-1 protein in $\mathrm{H}$. perforatum tissues mostly paralleled with the mRNA levels. In situ RNA hybridization localized the hyp-1 transcripts predominantly in vascular tissues in root and stem, while in leaf the mRNA levels were high also in mesophyll cells in addition to vasculature. Our results indicate that the studied $P R-10$ genes are likely to contribute to the defense responses in $\mathrm{H}$. perforatum. Furthermore, despite the location of the hyp-1 transcripts in vasculature, no support for the transportation of the Hyp-1 protein to dark glands was found in the current study. The present results together with earlier data question the role of the hyp-1 as a key gene responsible for the hypericin biosynthesis in dark glands of $H$. perforatum.

Keywords: St. John's wort, pathogenesis-related, PR proteins, defense response, gene expression, abscisic acid, salicylic acid, wounding

\section{INTRODUCTION}

Pathogenesis-related (PR) proteins constitute of a large group of proteins in higher plants often associated in plant defense responses. Based on sequence homology and biological activities, these proteins are classified into 17 different families (van Loon et al., 2006; Agarwal and Agarwal, 2014). The PR-10 subfamily is the largest family with members reported in numerous plant species and it includes major food and tree pollen allergens (Radauer and Breiteneder, 2007; Fernandes et al., 2013; Nakamura and Teshima, 2013). The members of the PR-10 protein family share 
common features such as low-molecular weight (15-20 kDa) with typically acidic $\mathrm{p}$, similar three-dimensional structure as well as conserved P-loop region, and usually cytosolic location (Liu and Ekramoddoullah, 2006; Fernandes et al., 2013; Agarwal and Agarwal, 2014).

The biological significance of the PR-10 proteins is not well understood but they are proposed to have a wide range of roles in plants. Association of the PR-10 proteins in plant defense has been suggested since many of the proteins are induced or their expression is up-regulated under various biotic or abiotic stress conditions, and some members exhibit antimicrobial or ribonuclease activity (Liu and Ekramoddoullah, 2006; Fernandes et al., 2013; Agarwal and Agarwal, 2014). There are also several reports of the up-regulation of the PR-10 gene expression by plant hormones and other signaling molecules transmitting plant defense responses (Pulla et al., 2010; Takeuchi et al., 2011; Jain et al., 2012; Agarwal and Agarwal, 2014). Structural studies have implied that the role of PR-10 proteins could be related to the binding and transportation of various hydrophobic ligands involved in plant development and defense-related signaling (Radauer et al., 2008; Fernandes et al., 2009, 2013). Few PR10 members have also been proposed to perform an enzymatic condensation reaction between the ligands they bind (Bais et al., 2003; Lee and Facchini, 2010).

Many plant species have been reported to contain more than one PR-10 protein (Schenk et al., 2009; Bahramnejad et al., 2010; Lebel et al., 2010; Xie et al., 2010; Lee et al., 2012). The significance of the multiple closely related genes in a single plant species is not clear but they may contribute to the diversification of functions between the PR-10 genes (Lebel et al., 2010). For example in peach, two Pru $\mathrm{p} 1$ protein isoforms have been reported to differ in their RNA hydrolysis and ligand binding activities (Zubini et al., 2009). In lupin, birch, grapevine, and ginseng, the members of the PR-10 gene family showed variable expression patterns in various tissues or in response to stress conditions indicating functional diversification between the family members (Pinto et al., 2005; Schenk et al., 2006; Lebel et al., 2010; Lee et al., 2012; He et al., 2013).

Hypericum perforatum L., commonly known as St. John's wort, is a herbaceous perennial plant that has received considerable interest due to its medicinal properties. The plant is widely utilized for the treatment of mild to moderate depression, and the efficacy of the plant crude extracts has been confirmed by several clinical and pharmacological studies (reviewed in Russo et al., 2014). The medicinal properties of the plant are attributed to secondary metabolites called hypericins and hyperforins that are accumulating in dark and translucent glands, respectively, in the aerial parts of the plant, especially in reproductive parts (Karppinen and Hohtola, 2008). There are also evidences supporting the biosynthesis of hypericins in the dark glands (Zobayed et al., 2006; Kornfeld et al., 2007; Karppinen et al., 2008; Košuth et al., 2011). To date, one PR10 gene from $H$. perforatum, called hyp-1, has been described, and its function has been suggested to be related with the biosynthesis and binding/transportation of hypericin (Bais et al., 2003; Michalska et al., 2010) as well as plant defense under stress conditions (Košuth et al., 2013). The objective of the present study was to investigate the presence of PR-10 family genes in $H$. perforatum. Here we report molecular cloning and expression analysis of three previously unidentified $H$. perforatum cDNAs with sequence homology to hyp-1 and genes encoding class PR10 proteins of other species. The expression of the three $P R-10$ genes along with hyp-1 were examined in various $H$. perforatum tissues as well as following wounding and treatments with stressrelated signaling molecules to assess their potential contribution in plant defense. Furthermore, the hyp-1 expression was analyzed at protein and cellular levels in order to obtain more detailed information of its location in the plant.

\section{MATERIALS AND METHODS}

\section{Plant Material}

The H. perforatum L. plants of Finnish origin were grown in field conditions in the Botanical Gardens of the University of Oulu, Finland. Tissue samples (stem, root, leaf, and flower bud) were collected from the plants at the early stage of flowering. The collected leaves were dissected into leaf margins that contained dark glands and into leaf interior parts that were free of dark glands. Immediately after excision, all tissues were frozen in liquid nitrogen and stored at $-80^{\circ} \mathrm{C}$ until they were used for RNA isolation, protein extraction and the determination of hypericins. Alternatively, tissues were fixed overnight at $4^{\circ} \mathrm{C}$ in $4 \%(\mathrm{w} / \mathrm{v})$ paraformaldehyde and $0.25 \%(\mathrm{v} / \mathrm{v})$ glutaraldehyde in $0.1 \mathrm{M}$ sodium phosphate buffer ( $\mathrm{pH}$ 7.0) for in situ RNA hybridization analysis. For stress treatments, the leaves of the plants were either wounded or sprayed with solutions of stressrelated phytohormones $( \pm)$-abscisic acid (ABA; Sigma, St. Louis, MO, USA) or salicylic acid (SA; Sigma). Concentrations of the phytohormones, $100 \mu \mathrm{M}$ of ABA and $10 \mathrm{mM}$ of SA, were selected based on previously reported studies (Bahramnejad et al., 2010; Pulla et al., 2010). Wounding of the leaves was carried out by making parallel incisions with a razor blade lengthwise on leaves. The leaf samples were collected at $0,3,6,10,24$, and $48 \mathrm{~h}$ after each treatment, immediately frozen in liquid nitrogen and stored at $-80^{\circ} \mathrm{C}$ until they were used for RNA isolation.

\section{Isolation of RNA and CDNA Preparation}

Total RNA was isolated from different tissues of $H$. perforatum according to Jaakola et al. (2001). The cDNA was synthesized from the total RNA using SuperScript III reverse transcriptase (Invitrogen, Carlsbad, CA, USA) with random primers according to the manufacturer's instructions. The cDNA was purified from contaminating genomic DNA by using the method described by Jaakola et al. (2004).

\section{Isolation of $\boldsymbol{H}$. perforatum PR-10 Genes}

To isolate $H$. perforatum $P R-10$ genes, previously identified plant $P R-10$ family genes were aligned and degenerate oligonucleotide primers were designed based on identified conserved regions. Degenerate primers 5' ${ }^{\prime}$-ARATHATHGARGGNGAYG-3' (forward primer) and 5'-RRTAYTCYTCNACYTGYT-3' (reverse primer) were used for amplification of $P R-10$ genes from $H$. perforatum cDNA. PCR reactions were performed 
with DyNazyme ${ }^{\mathrm{TM}}$ II DNA polymerase (Finnzymes, Espoo, Finland) under conditions: initial denaturation at $94^{\circ} \mathrm{C}$ for $4 \mathrm{~min}$, followed by 7 cycles at $94^{\circ} \mathrm{C}$ for $1 \mathrm{~min}, 70^{\circ} \mathrm{C}$ for $3 \mathrm{~min}$, ramp rate of $0,1^{\circ} \mathrm{C} / \mathrm{s}$ to $36^{\circ} \mathrm{C}$ and $72^{\circ} \mathrm{C}$ for $2 \mathrm{~min}$, followed by 35 cycles at $94^{\circ} \mathrm{C}$ for $1 \mathrm{~min}, 40^{\circ} \mathrm{C}$ for $2 \mathrm{~min}$, and $72^{\circ} \mathrm{C}$ for $2 \mathrm{~min}$, and final extension at $72^{\circ} \mathrm{C}$ for $5 \mathrm{~min}$. The amplified PCR products were gel-purified using a Montage ${ }^{\circledR}$ DNA Gel Extraction Kit (Millipore, Bedford, MA, USA) and ligated into a pGEM-T Easy vector (Promega, Madison, WI, USA). Sequencing was performed by using an ABI 3730 DNA sequencer (Applied Biosystems, Foster City, CA, USA) with a BigDye Terminator Cycle Sequencing Kit (Applied Biosystems). The $3^{\prime}$ and $5^{\prime}$ cDNA ends were isolated using a SMART ${ }^{\mathrm{TM}}$ RACE cDNA Amplification Kit (Clontech, Palo Alto, CA, USA). The nucleotide sequences of HpPR10.1 (hyp-1), HpPR10.2, HpPR10.3, and $H P P R 10.4$ were deposited to GenBank under accession numbers KU565780, KU565781, KU565782, and KU565783, respectively.

\section{Sequence Analysis}

For alignment and phylogenetic analysis of the H. perforatum PR10 sequences, amino acid sequences of previously characterized PR-10 family proteins of other species were obtained from GenBank and aligned with $H$. perforatum PR-10 sequences by using Clustal Omega program. A phylogenetic tree was constructed by using the neighbor-joining method with the MEGA software, version 6.06. The reliability of the tree was evaluated by a bootstrap analysis with 1000 replicates. The predicted protein molecular weight was calculated using Compute $\mathrm{pI} / \mathrm{Mw}$ tool (ExPASy Server). Signal peptide prediction was carried out using online tools SignalP 4.1 Server (Petersen et al., 2011) and Signal-BLAST, and the prediction of transmembrane domains was performed by using TMHMM Server v 2.0.

\section{Relative Quantification by Real-Time PCR}

Real-time quantitative reverse transcription PCR (qRT-PCR) analyses were performed with a LightCycler ${ }^{\circledR} 480$ instrument and software (Roche, Basel, Switzerland). The transcript abundance of the isolated $H$. perforatum $P R-10$ genes was detected using a LightCycler SYBR Green I Master qPCR Kit (Roche). The PCR conditions were an initial incubation at $95^{\circ} \mathrm{C}$ for $10 \mathrm{~min}$ followed by 45 cycles at $95^{\circ} \mathrm{C}$ for $10 \mathrm{~s}, 60^{\circ} \mathrm{C}$ for $20 \mathrm{~s}$, and $72^{\circ} \mathrm{C}$ for $10 \mathrm{~s}$. The gene-specific primer sequences used for the qRT-PCR analysis are shown in Table 1. For relative quantification of the PCR products, glyceraldehyde-3-phosphate dehydrogenase (GAPDH; GenBank Accession No. GU014528) was employed as a control gene. The results were verified by using $18 S$ rRNA (GenBank Accession No. AF206934) as a control gene. The results were calculated with LightCycler ${ }^{\circledR}$ 480 software (Roche), using the calibrator-normalized PCR efficiency-corrected method (Technical note No. LC 13/2001, Roche).

The specificities of the amplified qRT-PCR products were verified by a melting curve analysis. The obtained PCR products were further subjected to agarose electrophoresis, followed by gel extraction using a Montage ${ }^{\circledR}$ DNA Gel Extraction Kit (Millipore) and sequenced as described above to confirm the amplification of the desired product.

\section{In Situ RNA Hybridization Analysis}

Fixed $H$. perforatum tissues were embedded in paraffin, sectioned, de-paraffined and rehydrated as described earlier (Karppinen et al., 2008). Digoxigenin (DIG)-labeled hyp-1 sense and antisense RNA probes were obtained by in vitro transcription from a linearized plasmid containing a fragment of hyp-1 cDNA. For the plasmid construction, a 312-bp fragment from the coding region of hyp-1 was amplified from $H$. perforatum cDNA by PCR with DyNazyme ${ }^{\mathrm{TM}}$ II DNA polymerase (Finnzymes) using primers 5'-AGGCATTGGTCCTTGAACG-3' (forward) and 5' CAGGCTTGGGATGATAGGAG-3' (reverse) under standard PCR conditions. The PCR product was gel-purified, ligated into a pGEM-T Easy vector (Promega), and sequenced as described above to confirm the amplification of the desired product. In vitro transcription of the probes was performed from the linearized plasmid with either T7 or SP6 RNA polymerase using a DIG RNA Labeling Kit (Roche) according to the manufacturer's instructions.

In situ RNA hybridization analysis was performed as described previously (Karppinen et al., 2008) with the exception that the hybridization with the RNA probes was carried out at $54^{\circ} \mathrm{C}$. The hyp-1 sense probe was used in negative control sections. The sections were examined and photographed under a light microscope (Nicon Optiphot-2; Nikon Corporation, Tokyo, Japan) or scanned with a confocal laser scanning microscope (LSM-5 Pascal; Zeiss, Jena, Germany).

\section{Immunoblotting Analysis}

Proteins were isolated from $H$. perforatum tissues using a method described by Karppinen et al. (2010). The protein concentration of the extracts was determined according to Bradford (1976), using bovine serum albumin (Sigma) as a standard. Samples containing $30 \mu \mathrm{g}$ of proteins were separated with sodium dodecyl sulfate-polyacrylamide gel electrophoresis (SDS-PAGE), using $12 \%$ resolving and $3 \%$ stacking gels. The separation was conducted using a Mini-Protean II electrophoresis system

TABLE 1 | Gene-specific primers used for quantitative reverse transcription PCR (qRT-PCR) analyses.

\begin{tabular}{|c|c|}
\hline Gene & Primer sequence $5^{\prime}-3^{\prime}$ \\
\hline \multirow[t]{2}{*}{ HpPR10.1 (hyp-1) } & CAGGCTGTITAAGGCATTGGTC (forward) \\
\hline & GGGATGTCCATCAACGAAAGTG (reverse) \\
\hline \multirow[t]{2}{*}{ HpPR10.2 } & AGAAATCAAGGTCGGACAAGAG (forward) \\
\hline & CGAGGAAACAAGACCATAGAAC (reverse) \\
\hline \multirow[t]{2}{*}{ HpPR10.3 } & GAGGAAATCAAGCTAGGGCAAG (forward) \\
\hline & TGACGACGACTATTGCACACAC (reverse) \\
\hline \multirow[t]{2}{*}{ HpPR10.4 } & GGCACAGGAAGCAAGGGTAAG (forward) \\
\hline & GGGTAAACAAGGCCACCTCAG (reverse) \\
\hline \multirow[t]{2}{*}{$H p G A P D H$} & ATGGACCATCAAGCAAGGACTG (forward) \\
\hline & GAAGGCCATTCCAGTCAACTTC (reverse) \\
\hline
\end{tabular}


(Bio-Rad, Hercules, CA, USA) at 200 V. After electrophoresis, the proteins were either visualized with Coomassie Brilliant Blue R-250 (Merck, Darmstadt, Germany) or electroblotted for immunodetection onto polyvinylidene difluoride (PVDF) membrane (Bio-Rad) by using a Mini Trans-Blot Electrophoretic Transfer Cell (Bio-Rad) at $100 \mathrm{~V}$ for $2 \mathrm{~h}$. The immunological detection of Hyp-1 protein was performed as described previously (Karppinen et al., 2010). Intensities of each protein band were quantified using Quantity One software (Bio-Rad). Samples from three independent plants were employed for analyses.

\section{Production of Recombinant Hyp-1 Protein}

The coding region of the hyp-1 gene was amplified from H. perforatum cDNA by PCR, using forward primer $5^{\prime}$ CTATTTTAACATTTGGATCCATGGCGGCGTA-3' (the trans lation start codon is in bold and the BamHI site is underlined) and reverse primer 5'-GCAAAG GGTACCTTAAGCGAAAACTTCAGGA-3' (the translation stop codon is in bold and the $K p n I$ site is underlined) under standard PCR conditions. The PCR product was gel-purified and ligated into $\mathrm{BamHI} / \mathrm{KpnI}$ site of a pQE30 expression vector (Qiagen GmbH, Hilden, Germany). The obtained recombinant plasmid was transferred into Escherichia coli host strain M15 [pREP4] (Qiagen). The E. coli cells were grown in Luria-Bertani liquid medium in the presence of ampicillin $\left(100 \mu \mathrm{g} \mathrm{mL}^{-1}\right)$ and kanamycin $\left(25 \mu \mathrm{g} \mathrm{mL}{ }^{-1}\right)$ at $37^{\circ} \mathrm{C}$ until the $D_{600}$ of the culture reached 0.6 . The cells were induced by $0.5 \mathrm{mM}$ isopropyl thio- $\beta$-D-galactoside (IPTG) for $4 \mathrm{~h}$ at $37^{\circ} \mathrm{C}$. The recombinant Hyp-1 protein containing an additional hexahistidine tag at the N-terminus was purified from the E. coli cells as described previously (Karppinen et al., 2008).

\section{Determination of Hypericins}

HPLC-DAD was used for the determination of hypericin, pseudohypericin, protohypericin, and protopseudohypericin from different $H$. perforatum tissues as described previously (Karppinen and Hohtola, 2008). Samples from three individual plants were employed for analyses.

\section{Statistical Analysis}

Quantitative results of analyses of gene expression, protein levels and content of hypericins are presented in terms of means \pm SEs of at least three biological replicates. The effects of stress treatments on gene expression were analyzed with Student's $t$-Test by using SPSS Statistics program, version 22 (IBM, New York, NY, USA).

\section{RESULTS}

\section{Cloning and Sequence Analysis of $P R-10$ Genes}

In a search for $H$. perforatum $P R-10$ genes, four different nucleotide sequences were obtained with a homology-based PCR-method designated to target conserved regions of the $P R-10$ genes. The first sequence (HpPR10.1) was identified as hyp1 gene that was first described and indicated for hypericin biosynthesis in $H$. perforatum by Bais et al. (2003). The other three genes, named according to usual nomenclature as $H p P R 10.2, H p P R 10.3$, and $H p P R 10.4$, were isolated in full-length and they showed 79,80 , and $80 \%$ sequence identity, respectively, at nucleotide level to hyp-1 gene (Table 2). All the isolated genes had a coding sequence (CDS) of $480 \mathrm{bp}$ predicted to encode protein of 159 amino acids with a calculated molecular mass of $17.75-17.84 \mathrm{kDa}$ and a theoretical $\mathrm{pI}$ ranging from 5.54 to 6.16 (Table 2). These protein features coincide well with those typically reported for PR-10 family proteins (Liu and Ekramoddoullah, 2006; van Loon et al., 2006; Fernandes et al., 2013) and earlier for hyp-1 (Bais et al., 2003; Michalska et al., 2010). The proteins are likely to be cytoplasmic as no signal peptides or trans-membrane domains were detected in their sequences.

Multiple sequence alignment analysis showed that the predicted amino acid sequences of the isolated $H$. perforatum PR-10 genes (HpPR10.1, HpPR10.2, HPPR10.3, and HpPR10.4) had high homologies with other members of the PR-10 family proteins (Figure 1). All the four $H$. perforatum PR-10 sequences were found to contain a glycine-rich P-loop region (G-XG-G-X-G) that is reported to be conserved among PR-10 proteins (Fernandes et al., 2013) and share similar Bet v 1 family signature motif region as described earlier for Hyp-1 by Bais et al. (2003). Phylogenetic analysis demonstrated that H. perforatum PR-10 sequences grouped as their own cluster similarly to other PR-10 proteins that also tended to cluster together with the homologs of the same taxonomic group (Figure 1). This type of clustering has been reported typical among PR-10 proteins and suggest gene duplication events

TABLE 2 | Characteristics of the sequences of $H$. perforatum PR-10 genes and their coding sequence (CDS) identity to each other.

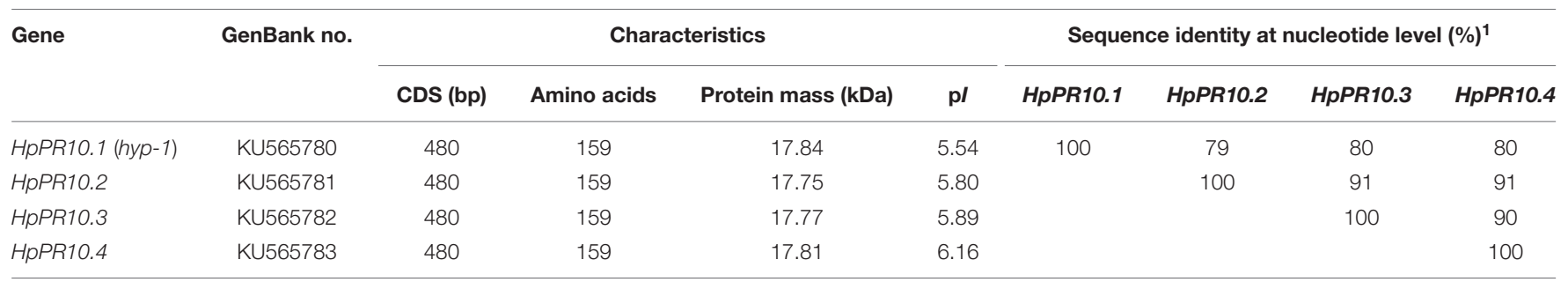

${ }^{1}$ The values were obtained from sequence alignments on Clustal Omega. CDS, coding sequence. 

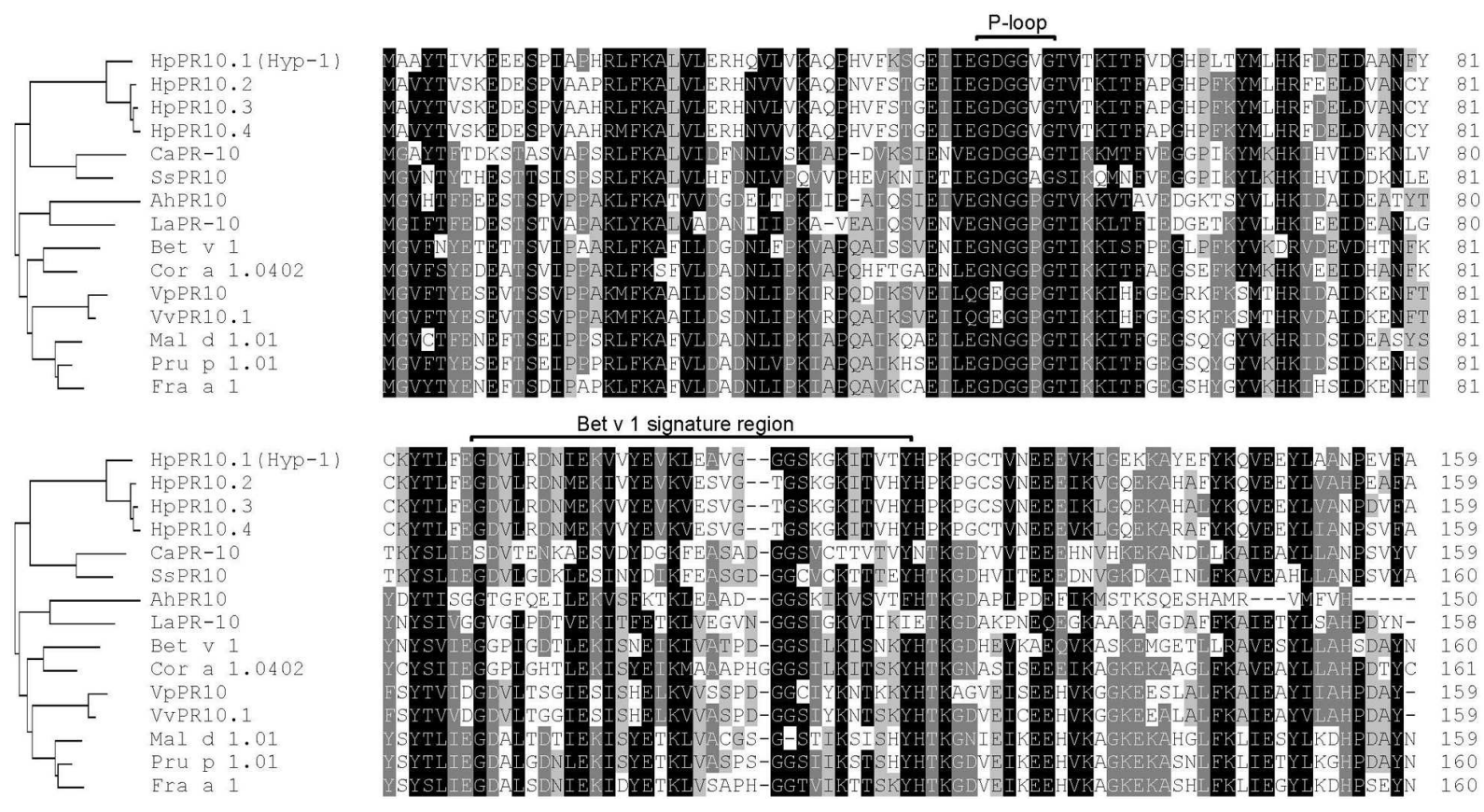

FIGURE 1 | Comparison of the deduced amino acid sequences of Hypericum perforatum PR-10 genes with other PR-10 family proteins. The conserved $\mathrm{P}$-loop and Bet $\mathrm{v} 1$ family motif signature region are showed in the alignment. A neighbor-joining tree based on the alignment is shown in the left. The GenBank accession numbers are as follows: Arachis hypogaea AhPR10 (AAU81922), Betula pendula Bet v 1 (CAB02159), Capsicum annuum CaPR-10 (AAF63519), Corylus avellana Cor a 1.0402 (AAG40329), Fragaria × ananassa Fra a 1 (CAJ29538), Lupinus albus LaPR-10 (CAA03926), Malus domestica Mal d 1.01 (AAX18288), Prunus dulcis $\times$ P. persica Pru p 1.01 (ACE80940), Solanum surattense SsPR10 (AAU00066), Vitis pseudoreticulata VpPR10 (ABC86747), and V. vinifera VvPR10.1 (CAC16166). The HpPR10.1 (Hyp-1), HpPR10.2, HpPR10.3, and HpPR10.4 sequences have been deposited in GenBank under accession numbers KU565780, KU565781, KU565782, and KU565783, respectively.

during evolution (Radauer and Breiteneder, 2007; Lebel et al., 2010).

\section{Expression of $P R-10$ Genes in $H$. perforatum Tissues}

The transcript levels of the isolated $P R-10$ genes were examined in different $H$. perforatum tissues with a qRT-PCR. All the genes were expressed at detectable levels in all tissues but with slightly variable expression patterns. Generally, the expression of all the genes was relatively high in leaf tissues, with no marked difference between leaf margin that contained dark glands and leaf interior part free of dark glands (Figure 2). Furthermore, the expression of all the genes was relatively low in stem tissue in comparison to leaf tissues and especially low in flower buds (Figure 2), the primary site for the accumulation of hypericins (Supplementary Figure S1). Instead, the expression levels of HpPR10.1 (hyp-1; Figure 2A) and HpPR10.4 (Figure 2D) were relatively low in root tissues while $H P P R 10.2$ (Figure 2B) and HPPR10.3 (Figure 2C) had higher relative transcript levels in root. All the genes showed higher expression levels in younger parts of root closer to root tip compared to upper parts of root (data not shown).

\section{In Situ RNA Localization of hyp-1}

The exact localization of the hyp-1 gene expression in H. perforatum tissues was studied by in situ RNA hybridization.
The study revealed that the hyp-1 transcripts were mainly associated with leaf mesophyll as well as with the differentiated cells of vascular tissue in leaf, stem, and root. In stem, a blue signal for transcripts was mainly localized in both phloem and xylem cells in the area of vascular tissue but a weak signal was also present in the parenchyma cells under the stem epidermis (Figure 3A). The probe specificity was confirmed by the absence of any signal in the negative control sections of the stem hybridized with sense probe (Figure 3B). In the stem xylem, the signal was associated with xylem parenchyma cells in both the secondary and the primary xylem (Figure 3C). In the stem phloem, the signal was associated with parenchyma cells (Figure 3C) and small companion cells next to larger sieve elements (Figure 3D). The sieve elements showed no apparent signal. The mRNA was also apparent in cells surrounding specific secretory canals (Figure 3D), named type A canals earlier by Ciccarelli et al. (2001). In root, the transcripts were present in xylem parenchyma cells, in pericycle cells as well as in cells within the phloem (Figure 3E). No signal was detected in the corresponding areas of the negative control sections of roots (Figure 3F). In leaves, the mRNA was associated with both palisade and spongy parenchyma cells (Figure 3G). The signal was also detected in vascular tissues of leaves and was mostly associated with the cells surrounding the type A canals of the phloem (Figure $3 \mathbf{H}$ ). No detectable signal was found in the cells of dark glands. 

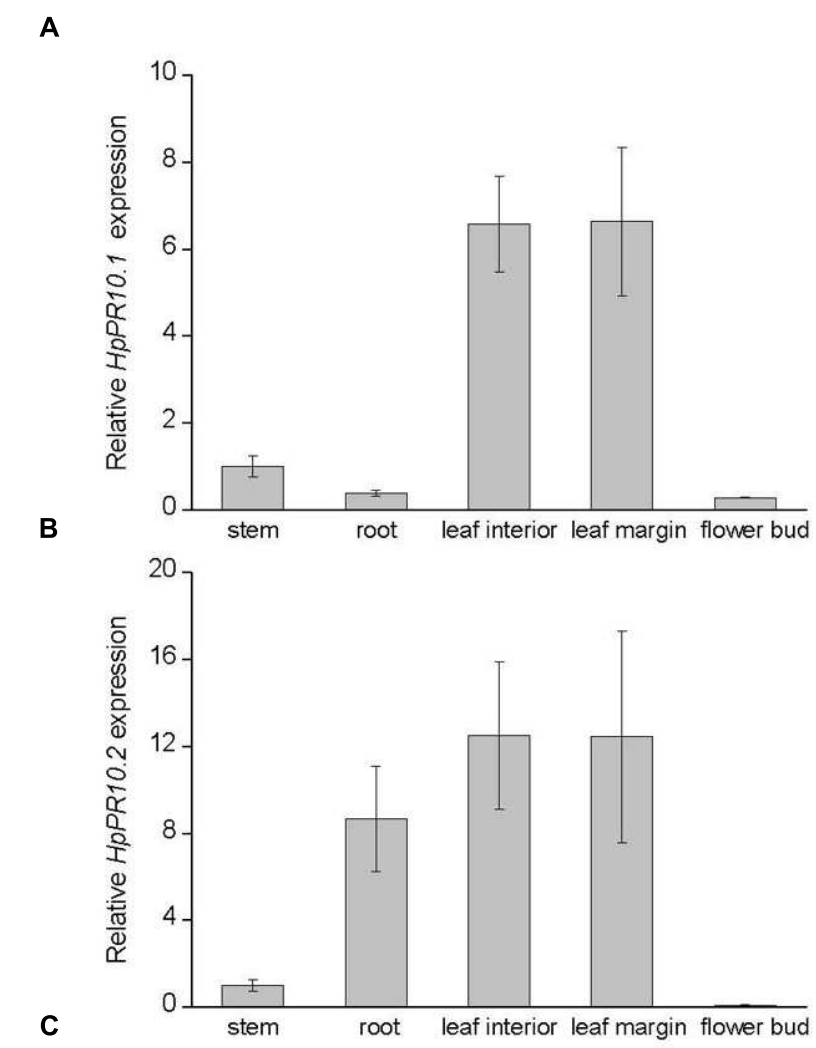

C

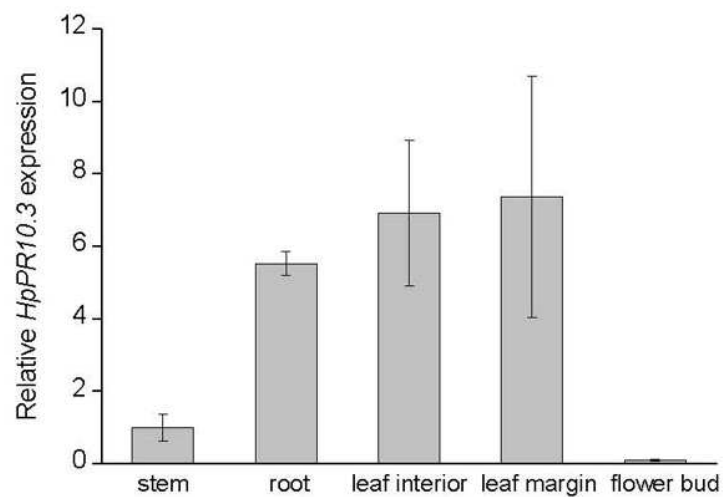

D

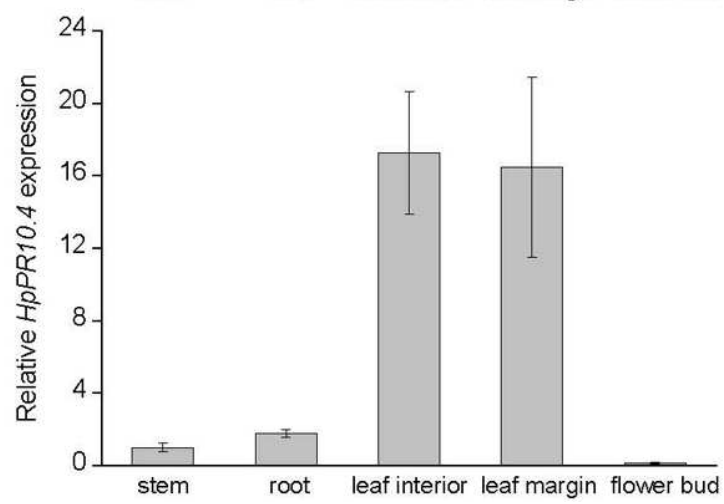

FIGURE 2 | Expression of HpPR10.1 (hyp-1; A), HpPR10.2 (B), HpPR10.3 (C), and HpPR10.4 (D) in H. perforatum tissues. The relative expression of the genes was quantified by qRT-PCR and normalized to GAPDH. Values represent means $\pm \mathrm{SE}$ of three biological replicates.
Neither signal was detected in negative controls of leaf sections (Figure 3I).

\section{Immunoblotting Analysis of Hyp-1 Protein in $\boldsymbol{H}$. perforatum Tissues}

We also examined the presence of Hyp-1 at protein level by immunoblotting analysis in the same $H$. perforatum tissues used for qRT-PCR analysis. In immunoblots, the antibody raised against Hyp-1 reacted with a purified recombinant Hyp1 protein of about $18.5 \mathrm{kDa}$ (Figure 4A) and a polypeptide of approximately $18 \mathrm{kDa}$ in extracts of $H$. perforatum tissues (Figure 4B). The size coincides with the predicted molecular mass of $17.8 \mathrm{kDa}$ for natural Hyp-1 protein that was calculated using bioinformatics tools and with the size that has previously been reported for Hyp-1 protein by other authors (Bais et al., 2003; Michalska et al., 2010). The small increase in the recombinant Hyp-1 protein size compared with the natural Hyp-1 protein is due to the presence of a His-tag at the $\mathrm{N}$-terminus of the recombinant protein (12 additional amino acids). Immunoblotting analysis of $H$. perforatum tissues showed the highest level of Hyp-1 protein to be present in stem and leaf tissues while markedly lower levels were detected in root and especially flower buds (Figure 4B). Leaf margin containing dark glands and leaf interior part free of dark glands contained equal amounts of Hyp-1 protein (Figure 4B). The SDS-PAGE analysis demonstrated an equal loading of proteins to the gel with equal amounts of Rubisco subunits between the samples of leaf margin and leaf interior. The portion of the Rubisco subunits in the total protein loaded to the gel is high in stem and leaf samples but in flower buds and especially in root the Rubisco subunits form lower portion in the total proteins. This may cause some elevation in the level of Hyp1 protein in immunoblot in these tissues relative to the green tissues.

\section{Expression of $P R-10$ Genes in Response to Stress Treatments}

To examine whether the expression of the HPPR10 genes are affected by different stress treatments, $H$. perforatum leaves were either wounded or treated with stress-related signaling molecules salicylic acid (SA; $10 \mathrm{mM}$ ) or abscisic acid (ABA; $100 \mu \mathrm{M})$. As shown in Figure 5, the treatment with SA significantly upregulated the expression of $H p P R 10.2, H p P R 10.3$, and $H p P R 10.4$ in $H$. perforatum leaves. Especially the transcripts of $H p P R 10.4$ were highly induced by SA already $3 \mathrm{~h}$ after the treatment, and the expression gradually declined after that. The expression of $H P P R 10.2$ peaked at $6 \mathrm{~h}$ and $H P P R 10.3$ at $10 \mathrm{~h}$ after the SA treatment. Also the treatment with ABA significantly elevated $H P P R 10.2, H p P R 10.3$, and HPPR10.4 expression after $6 \mathrm{~h}$ of the treatment with declining trend in the expression detected thereafter. Mechanical wounding of leaves significantly upregulated the expression of $H P P R 10.3$ and $H P P R 10.4$ peaking $6 \mathrm{~h}$ after the treatment. Also $H p P R 10.2$ expression was elevated by the wounding but there seemed to be high variation between individual plants in the level of response to the treatment. None of the treatments significantly increased the expression 


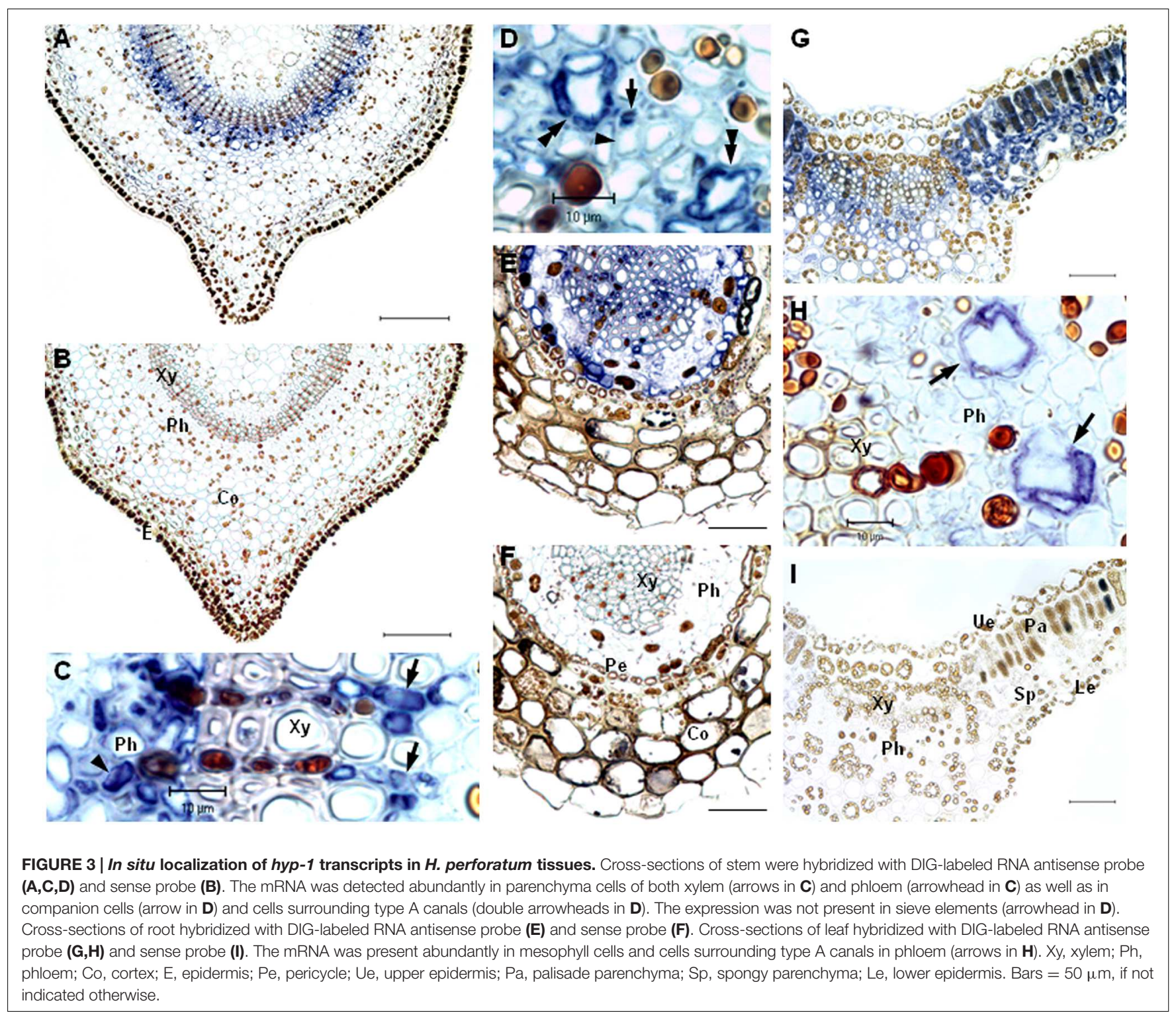

of HpPR10.1 (hyp-1) in H. perforatum leaves in the present study.

\section{DISCUSSION}

Many plant species have been found to contain several proteins belonging to the PR-10 family. Although the role of the PR-10 genes is not entirely known, functional diversification between the genes in plant development and protein-based defense has been suggested (Lebel et al., 2010). The presence of $P R-10$ genes has also been reported in genus Hypericum (Bais et al., 2003; Jin et al., 2010). In the present study, the search for sequences encoding PR-10 proteins in $H$. perforatum revealed three previously unidentified members that were closely related to earlier described hyp-1, a phenolic coupling protein suggested to be involved in biosynthesis and binding/transportation of hypericin (Bais et al., 2003; Michalska et al., 2010). The isolated H. perforatum $P R-10$ genes shared 79 to $80 \%$ identity at nucleotide level with hyp-1. The characteristics of the proteins, which were predicted to be small, acidic and cytosol-located, coincide well with those typically reported for PR-10 family proteins (Liu and Ekramoddoullah, 2006; Fernandes et al., 2013; Agarwal and Agarwal, 2014). Furthermore, their sequences contained features common to PR-10 family proteins, such as a glycine-rich P-loop conserved among PR-10 proteins (Fernandes et al., 2013) and shared similar Bet v 1 family signature motif region as described earlier for Hyp-1 (Bais et al., 2003).

The expression of some PR-10 proteins is known to be induced under certain stress conditions or expressed only in some tissues while some are constitutively expressed (Agarwal and Agarwal, 2014). Based on our results, all the studied H. perforatum PR-10 genes were expressed in all analyzed 


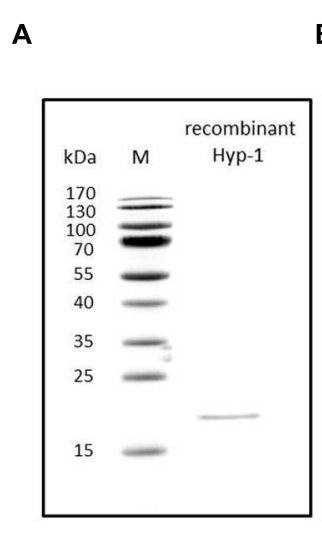

B

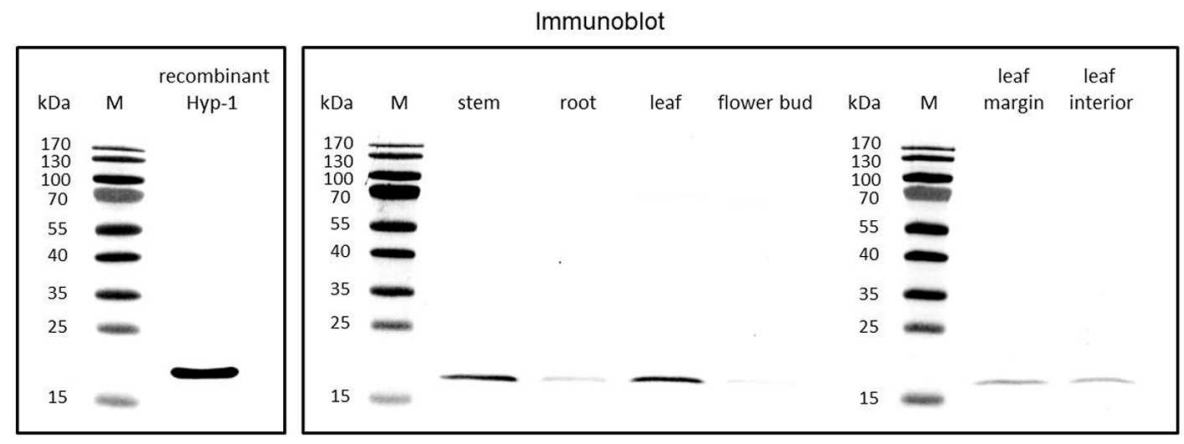

Relative intensity

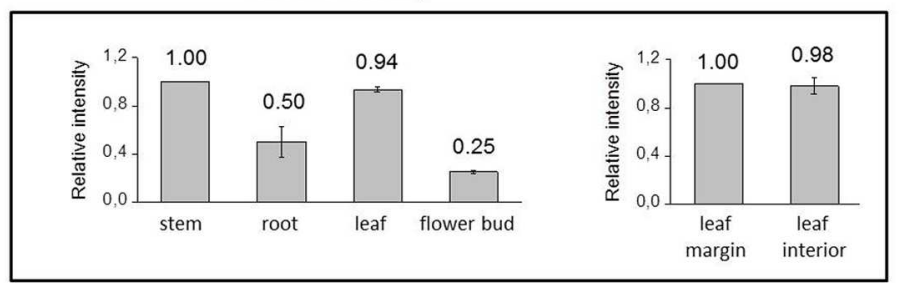

FIGURE 4 | Immunoblotting detection of Hyp-1 protein in $\boldsymbol{H}$. perforatum tissues. Coomassie Brilliant Blue stained SDS-PAGE gels and the corresponding immunoblots showing detection of Hyp-1 protein in samples of recombinant Hyp-1 protein (A) and H. perforatum tissues (B). Lane M, protein molecular mass marker, with size (kDa) indicated on the left. Relative intensity values for protein levels in immunoblots represent means \pm SE of three biological replicates.

tissues. Their expression was most highly associated with leaf tissues with lower transcript amounts found in stem and root tissues. Their expression differed from each other mostly in root tissue where expression of $H P P R 10.2$ and $H p P R 10.3$ was relatively high compared to relatively low expression of $H P P R 10.1$ (hyp-1) and HpPR10.4 indicating possible specialization in their function between organs. We also found that the expression of all the $H$. perforatum $P R-10$ genes was higher closer to the root tip. Earlier, Košuth et al. (2007) have reported that the hyp-1 expression pattern of ex vitro plants differ from the pattern of young in vitro seedlings, which showed a high level of expression in roots. We have also demonstrated earlier that the developmental stage of leaf affects the presence of Hyp-1 protein (Karppinen et al., 2010) supporting the suggestion that the $H$. perforatum $P R-10$ genes are likely to be developmentally regulated similarly to many other $P R-10$ genes (Liu and Ekramoddoullah, 2006; Kim et al., 2008; Pulla et al., 2010).
The expression of the $H P P R 10$ genes was analyzed in this study for the first time in reproductive parts of $H$. perforatum which are rich with dark glands which form the primary accumulation sites of hypericins. All the genes were expressed relatively low levels in flower buds with no relation to analyzed content of hypericins. The lack of correlation between the HPPR10 gene expression and the presence of dark glands was also confirmed by the similar expression levels of all the HPPR10 genes in both leaf margin rich with dark glands and leaf interior parts lacking dark glands. Neither in earlier studies the hyp-1 expression has been found to parallel with the presence of hypericins in the vegetative tissues of H. perforatum (Bais et al., 2003; Košuth et al., 2007) or in other species of genus Hypericum (Košuth et al., 2011).

Despite of numerous studies of hyp-1 expression in genus Hypericum, the expression has not previously been studied at a cellular level. In the present study, we examined for the first time the expression of hyp-1 gene in a cellular level by in situ RNA localization. The hyp-1 transcripts in $H$. perforatum stem 

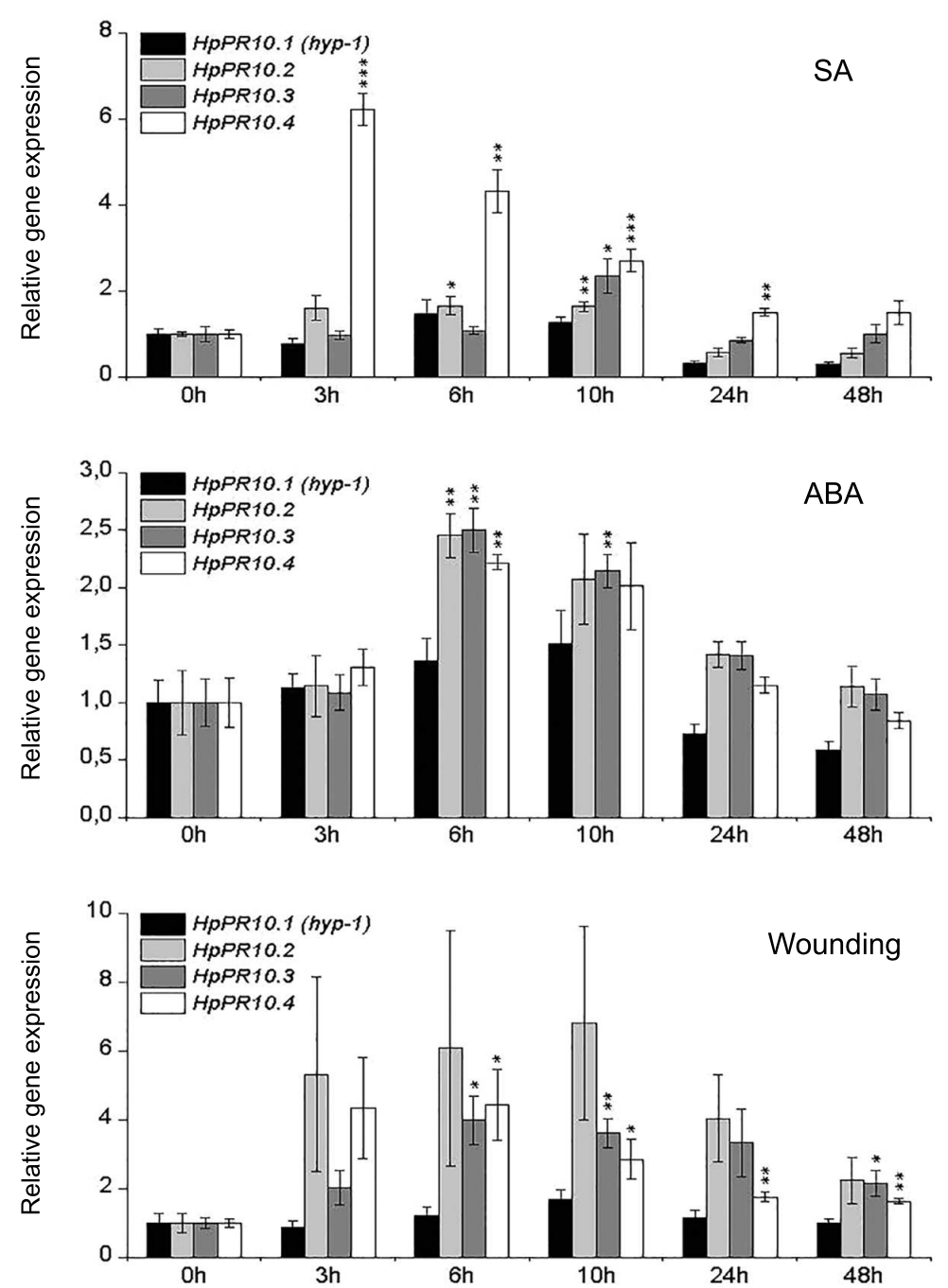

FIGURE 5 | Temporal expression patterns of HpPR10.1 (hyp-1), HpPR10.2, HpPR10.3, and HpPR10.4 in H. perforatum leaf tissues in response to treatments with SA (10 $\mathbf{m M})$, ABA $(100 \mu \mathrm{M})$ or wounding. The relative expression of the genes was quantified by qRT-PCR and normalized to GAPDH. Values represent means \pm SE of at least three biological replicates. Asterisks indicate statistically significant difference in comparison to untreated control (0 h) in Student's $t$-Test at ${ }^{*} P \leq 0.05,{ }^{*} P \leq 0.01,{ }^{* * *} P \leq 0.001$.

and root were found to be present in vascular tissues while in leaves the transcripts were also highly associated with mesophyll cells in addition to vascular tissues but not in dark glands. In the vascular tissues, the expression was present in both xylem and phloem cells as well as type A canals. Type A canals have been described earlier for $H$. perforatum by Ciccarelli et al. (2001) but the meaning of the canals for the plant is unknown, although a function in transportation of photosynthates and phloem protectants were suggested. In root and stem, the hyp1 expression was highly associated with both xylem and phloem parenchyma cells and companion cells next to sieve elements as well as pericycle cells in root. The parenchyma cells in vascular tissue attend to the lateral transport of compounds, while the pericycle cells are known to be metabolically active and involved in the transport of compounds to and from the vascular bundle that they surround. Our results of the hyp-1 transcript localization are in agreement with the data obtained by Qian et al. (2012) who studied the cellular location at protein level in $H$. perforatum tissues and found the Hyp-1 protein to be present mainly in vascular tissues of both root and stem as well as in leaf mesophyll with no obvious signal in dark glands.

The expression and location of many PR-10 family proteins of various plant species have been found to be associated with vascular tissues (Breda et al., 1996; Pinto et al., 2005; Kim et al., 2008; Bahramnejad et al., 2010). The biological role of these proteins in the vasculature is not known although defensive role under stress conditions or binding/transportation of hydrophobic ligands have been suggested (Kim et al., 2008; Radauer et al., 2008; Fernandes et al., 2013). The location of the hyp-1 transcripts in cells of vasculature suggests a similar role. The inconsistent results of hyp-1 mRNA level with Hyp-1 protein 
level in $H$. perforatum stem found in the current study can be due to the higher stability of the Hyp-1 protein in stem or indicate the movement of the protein between organs through vasculature. However, the sequences of $H$. perforatum PR-10 proteins, like those of most identified PR-10 proteins, contain no recognizable amino-terminal signal peptide sequence for apoplastic secretion specific to xylem sap proteins (Liu and Ekramoddoullah, 2006; Agarwal and Agarwal, 2014). Since there are suggestions of the role of Hyp-1 in binding and transportation of ligand molecules related to defense and developmental processes (Michalska et al., 2010; Košuth et al., 2013), the possible symplastic mobility of the protein by via plasmodesmata into phloem sap of mature sieve elements needs to be investigated in the future.

Previous studies have evidenced that hypericin biosynthesis is likely to take place in dark glands of $H$. perforatum (Zobayed et al., 2006; Kornfeld et al., 2007; Karppinen et al., 2008; Košuth et al., 2011). However, as discussed above, the hyp-1 expression does not correlate with hypericin content or presence of dark glands in tissues of $H$. perforatum or other Hypericum species. In the present study, equal amounts of the Hyp-1 protein were found in leaf margin and leaf interior parts and, thus, neither our results provide any evidence that the Hyp-1 protein would be specifically associated or accumulating via transportation to the dark glands for its activity in the final stages of hypericin biosynthesis as suggested earlier (Bais et al., 2003). Our results are in agreement with the earlier study of Qian et al. (2012) who reported the presence of the Hyp-1 protein in leaf, stem and root of $H$. perforatum with no association in dark glands in leaves. These findings question the role of the hyp-1 as a key gene in the hypericin biosynthesis. However, our results cannot exclude the possibility that the Hyp-1 would attend to the biosynthesis/transportation/binding of toxic hypericin (Bais et al., 2003; Michalska et al., 2010) in tissues outside dark glands that also contain minor amounts of hypericins as detected in the current and previous studies (Bais et al., 2002; Gadzovska et al., 2007; Karppinen and Hohtola, 2008; Cui et al., 2010).

Plants are continuously exposed to various stresses in their natural environment. The function of PR-10 proteins is often associated in plant defense because many $P R-10$ genes are induced or their expression is up-regulated by different types of biotic and abiotic stresses, such as drought, cold, wounding, and pathogens, as well as stress-related signaling molecules (Pulla et al., 2010; Takeuchi et al., 2011; Agarwal and Agarwal, 2014). Thus, PR-10 family proteins are considered as potentially useful genes for crop improvement. Previously Košuth et al. (2013) described increased expression of hyp-1 in $H$. perforatum after wounding and treatment with Agrobacterium or ABA. ABAmediated signaling is known to play an important role in plant responses to environmental stresses and plant pathogens (Lee and Luan, 2012). Wounding of plants induces defense responses that resemble those induced by herbivores or pathogen attack. In the current study, we found that all the three newly isolated $P R-10$ genes were up-regulated in leaves of $H$. perforatum by wounding as well as by treatment with ABA and SA suggesting a role for the genes in plant defense. The role of SA is established in defense responses against plant pathogens as well as many types of abiotic stresses (Miura and Tada, 2014). In our study, especially the expression of $H P P R 10.4$ was rapidly and highly induced by $\mathrm{SA}$ indicating its special role in SA mediated defense responses. The differential gene expression patterns of the $H p P R 10$ genes in response to stress-related treatments may imply that they have gene-specific functions under different types of stress conditions. In the present study, hyp-1 levels were only slightly but not significantly induced by the tested stress treatments which is different to the results of Košuth et al. (2013). The inconsistency in results between the two studies can be due to the differences in the applied treatments (ABA concentration or ABA application method and extent of wounding) or differences in plant material. Depending on the developmental stage of the plant, responses can differ as discussed above.

\section{CONCLUSION}

We have isolated three previously unidentified $P R-10$ family genes from $H$. perforatum and studied their expression along with closely related hyp-1 in $H$. perforatum tissues and under various stress treatments. Our results show that these genes are constitutively but differently expressed in various $H$. perforatum tissues and their expression is also variably up-regulated by wounding and defense-related signaling molecules. The results suggest a role for these genes in contribution to the defense responses in $H$. perforatum with various functions. Since some $P R-10$ genes in other species have been reported to be expressed only in certain specific tissues or under certain stress conditions it cannot be excluded that $H$. perforatum would not have more PR10 proteins which are to be discovered in the future. Furthermore, the results of the current study do not support the location of the hyp-1 mRNA or Hyp-1 protein in dark glands or accumulation of the protein via transportation to the dark glands and, thus, question the role of hyp-1 as a key gene in the hypericin biosynthesis in dark glands of $H$. perforatum.

\section{AUTHOR CONTRIBUTIONS}

KK and ED performed the analyses. All authors (KK, ED, LJ, and $\mathrm{AH}$ ) have participated in preparation of the manuscript and have accepted the final version of the manuscript.

\section{ACKNOWLEDGMENTS}

This work was financially supported by the grants from the Finnish Cultural Foundation (Northern Ostrobothnia fund) and Oulu University Scholarship Foundation to KK.

\section{SUPPLEMENTARY MATERIAL}

The Supplementary Material for this article can be found online at: http://journal.frontiersin.org/article/10.3389/fpls.2016.00526

FIGURE S1 | The contents of hypericins ( $\left.\mathrm{mg} \mathrm{g}^{-1} \mathrm{DW}\right)$ in $\mathbf{H}$. perforatum tissues. Values represent means \pm SE of three biological replicates. 


\section{REFERENCES}

Agarwal, P., and Agarwal, P. K. (2014). Pathogenesis related-10 proteins are small, structurally similar but with diverse role in stress signaling. Mol. Biol. Rep. 41, 599-611. doi: 10.1007/s11033-013-2897-4

Bahramnejad, B., Goodwin, P. H., Zhang, J., Atnaseo, C., and Erickson, L. R. (2010). A comparison of two class 10 pathogenesis-related genes from alfalfa and their activation by multiple stresses and stress-related signaling molecules. Plant Cell Rep. 29, 1235-1250. doi: 10.1007/s00299-010-0909-6

Bais, H. P., Vepachedu, R., Lawrence, C. B., Stermitz, F. R., and Vivanco, J. M. (2003). Molecular and biochemical characterization of an enzyme responsible for the formation of hypericin in St. John's wort (Hypericum perforatum L.). J. Biol. Chem. 278, 32413-32422. doi: 10.1074/jbc.M301681200

Bais, H. P., Walker, T. S., McGrew, J. J., and Vivanco, J. M. (2002). Factors affecting growth of cell suspension cultures of Hypericum perforatum L. (St. John's wort) and production of hypericin. In Vitro Cell. Dev. Biol. Plant 38, 58-65. doi: 10.1079/IV2001253

Bradford, M. M. (1976). A rapid and sensitive method for the quantitation of microgram quantities of protein utilizing the principle of protein-dye binding. Anal. Biochem. 72, 248-254. doi: 10.1016/0003-2697(76)90527-3

Breda, C., Sallaud, C., El-Turk, J., Buffard, D., de Kozak, I., Esnault, R., et al. (1996). Defense reaction in Medicago sativa: a gene encoding a class $10 \mathrm{PR}$ protein is expressed in vascular bundles. Mol. Plant Microbe Interact. 9, 713-719. doi: 10.1094/MPMI-9-0713

Ciccarelli, D., Andreucci, A. C., and Pagni, A. M. (2001). Translucent glands and secretory canals in Hypericum perforatum L. (Hypericaceae): morphological, anatomical and histochemical studies during the course of ontogenesis. Ann. Bot. 88, 637-644. doi: 10.1006/anbo.2001.1514

Cui, X. H., Chakrabarty, D., Lee, E. J., and Paek, K. Y. (2010). Production of adventitious roots and secondary metabolites by Hypericum perforatum L. in a bioreactor. Bioresour. Technol. 101, 4708-4716. doi: 10.1016/j.biortech.2010.01.115

Fernandes, H., Bujacz, A., Bujacz, G., Jelen, F., Jasinski, M., Kachlicki, P., et al. (2009). Cytokinin-induced structural adaptability of a Lupinus luteus PR-10 protein. FEBS J. 276, 1596-1609. doi: 10.1111/j.1742-4658.2009.06892.x

Fernandes, H., Michalska, K., Sikorski, M., and Jaskolski, M. (2013). Structural and functional aspects of PR-10 proteins. FEBS J. 280, 1169-1199. doi: $10.1111 /$ febs. 12114

Gadzovska, S., Maury, S., Delaunay, A., Spasenoski, M., Joseph, C., and Hagège, D. (2007). Jasmonic acid elicitation of Hypericum perforatum L. cell suspensions and effects on the production of phenylpropanoids and naphtodianthrones. Plant Cell Tiss. Organ Cult. 89, 1-13. doi: 10.1007/s11240-007-9203-X

He, M., Xu, Y., Cao, J., Zhu, Z., Jiao, Y., Wang, Y., et al. (2013). Subcellular localization and functional analyses of a PR10 protein gene from Vitis pseudoreticulata in response to Plasmopara viticola infection. Protoplasma 250, 129-140. doi: 10.1007/s00709-012-0384-8

Jaakola, L., Pirttilä, A. M., Halonen, M., and Hohtola, A. (2001). Isolation of high quality RNA from bilberry (Vaccinium myrtillus L.) fruit. Mol. Biotechnol. 19, 201-203. doi: 10.1385/MB:19:2:201

Jaakola, L., Pirttilä, A. M., Vuosku, J., and Hohtola, A. (2004). Method based on electrophoresis and gel extraction for obtaining genomic DNA-free cDNA without DNase treatment. Biotechniques 37, 744-748.

Jain, S., Kumar, D., Jain, M., Chaudhary, P., Deswal, R., and Sarin, N. B. (2012). Ectopic overexpression of a salt stress-induced pathogenesis-related class 10 protein (PR10) gene from peanut (Arachis hypogaea L.) affords broad spectrum abiotic stress tolerance in transgenic tobacco. Plant Cell Tiss. Organ Cult. 109, 19-31. doi: 10.1007/s11240-011-0069-6

Jin, M. L., Ahn, J. C., Hwang, B., Park, H. S., Lee, H. S., and Choi, D. W. (2010). Isolation and functional analysis of cDNAs similar to Hyp-1 involved in hypericin biosynthesis from Hypericum erectum. Biol. Plant. 54, 725-729. doi: 10.1007/s10535-010-0129-5

Karppinen, K., and Hohtola, A. (2008). Molecular cloning and tissue-specific expression of two cDNAs encoding polyketide synthases from Hypericum perforatum. J. Plant Physiol. 165, 1079-1086. doi: 10.1016/j.jplph.2007.04.008

Karppinen, K., Hokkanen, J., Mattila, S., Neubauer, P., and Hohtola, A. (2008). Octaketide-producing type III polyketide synthase from Hypericum perforatum is expressed in dark glands accumulating hypericins. FEBS J. 275, 4329-4342. doi: $10.1111 /$ j.1742-4658.2008.06576.x
Karppinen, K., Taulavuori, E., and Hohtola, A. (2010). Optimization of protein extraction from Hypericum perforatum tissues and immunoblotting detection of Hyp-1 at different stages of leaf development. Mol. Biotechnol. 46, 219-226. doi: 10.1007/s12033-010-9299-9

Kim, S. T., Yu, S., Kang, Y. H., Kim, S. G., Kim, J. Y., Kim, S. H., et al. (2008). The rice pathogen-related protein 10 (JIOsPR10) is induced by abiotic and biotic stresses and exhibits ribonuclease activity. Plant Cell Rep. 27, 593-603. doi: 10.1007/s00299-007-0485-6

Kornfeld, A., Kaufman, P. B., Lu, C. R., Gibson, D. M., Bolling, S. F., Warber, S. L., et al. (2007). The production of hypericins in two selected Hypericum perforatum shoot cultures is related to differences in black gland structure. Plant Physiol. Biochem. 45, 24-32. doi: 10.1016/j.plaphy.2006.12.009

Košuth, J., Hrehorová, D., Jaskolski, M., and Čellárová, E. (2013). Stress-induced expression and structure of the putative gene hyp-1 for hypericin biosynthesis. Plant Cell Tiss. Organ Cult. 114, 207-216. doi: 10.1007/s11240-0130316-0

Košuth, J., Katkovčinová, Z., Olexová, P., and Čellárová, E. (2007). Expression of the hyp-1 gene in early stages of development of Hypericum perforatum L. Plant Cell Rep. 26, 211-217. doi: 10.1007/s00299-006-0240-4

Košuth, J., Smelcerovic, A., Borsch, T., Zuehlke, S., Karppinen, K., Spiteller, M., et al. (2011). The hyp-1 gene is not a limiting factor for hypericin biosynthesis in the genus Hypericum. Funct. Plant Biol. 38, 35-43. doi: 10.1071/ FP10144

Lebel, S., Schellenbaum, P., Walter, B., and Maillot, P. (2010). Characterisation of the Vitis vinifera PR10 multigene family. BMC Plant Biol. 10:184. doi: 10.1186/1471-2229-10-184

Lee, E. J., and Facchini, P. (2010). Norcoclaurine synthase is a member of the pathogenesis-related 10/Bet v1 protein family. Plant Cell 22, 3489-3503. doi: 10.1105/tpc. 110.077958

Lee, O. R., Pulla, R. K., Kim, Y. J., Balusamy, S. R. D., and Yang, D. C. (2012). Expression and stress tolerance of PR10 genes from Panax ginseng C. A. Meyer. Plant Biol. Rep. 39, 2365-2374. doi: 10.1007/s11033-011-0987-8

Lee, S. C., and Luan, S. (2012). ABA signal transduction at the crossroad of biotic and abiotic stress responses. Plant Cell Environ. 35, 53-60. doi: 10.1111/j.13653040.2011.02426.x

Liu, J. J., and Ekramoddoullah, A. K. M. (2006). The family 10 of plant pathogenesis-related proteins: their structure, regulation, and function in response to biotic and abiotic stresses. Physiol. Mol. Plant Pathol. 68, 3-13. doi: 10.1016/j.pmpp.2006.06.004

Michalska, K., Fernandes, H., Sikorski, M., and Jaskolski, M. (2010). Crystal structure of Hyp-1, a St. John's wort protein implicated in the biosynthesis of hypericin. J. Struct. Biol. 169, 161-171. doi: 10.1016/j.jsb.2009. 10.008

Miura, K., and Tada, Y. (2014). Regulation of water, salinity, and cold stress responses by salicylic acid. Front. Plant Sci. 5:4. doi: 10.3389/fpls.2014. 00004

Nakamura, R., and Teshima, R. (2013). Proteomics-based allergen analysis in plants. J. Proteomics 93, 40-49. doi: 10.1016/j.jprot.2013.03.018

Petersen, T. N., Brunak, S., von Heijne, G., and Nielsen, H. (2011). SignalP 4.0: discriminating signal peptides from transmembrane regions. Nat. Methods 8 , 785-786. doi: 10.1038/nmeth.1701

Pinto, M. P., Ribeiro, A., Regalado, A. P., Rodrigues-Pousada, C., and Ricardo, C. P. P. (2005). Expression of Lupinus albus PR-10 proteins during root and leaf development. Biol. Plant. 49, 187-193. doi: 10.1007/s10535-0057193-2

Pulla, R. K., Lee, O. R., In, J. G., Kim, Y. J., Senthil, K., and Yang, D. C. (2010). Expression and functional characterization of pathogenesis-related protein family 10 gene, PgPR10-2, from Panax ginseng C.A. Meyer. Physiol. Mol. Plant Pathol. 74, 323-329. doi: 10.1016/j.pmpp.2010.05.001

Qian, J., Wu, J., Yao, B., and Lu, Y. (2012). Preparation of a polyclonal antibody against hypericin synthase and localization of the enzyme in red-pigmented Hypericum perforatum L. plantlets. Acta Biochim. Pol. 59, 639-645.

Radauer, C., and Breiteneder, H. (2007). Evolutionary biology of plant food allergens. J. Allergy Clin. Immunol. 120, 518-525. doi: 10.1016/j.jaci.2007.07.024

Radauer, C., Lackner, P., and Breiteneder, H. (2008). The Bet v 1 fold: an ancient, versatile scaffold for binding of large, hydrophobic ligands. BMC Evol. Biol. 8:286. doi: $10.1186 / 1471-2148-8-286$ 
Russo, E., Scicchitano, F., Whalley, B. J., Mazzitello, C., Ciriaco, M., Esposito, S., et al. (2014). Hypericum perforatum: pharmacokinetic, mechanism of action, tolerability, and clinical drug-drug interactions. Phytother. Res. 28, 643-655. doi: $10.1002 /$ ptr.5050

Schenk, M. F., Cordewener, J. H. G., America, A. H. P., van't Westende, W. P. C., Smulders, M. J. M., and Gilissen, L. J. W. J. (2009). Characterization of PR-10 genes from eight Betula species and detection of Bet $\mathrm{v} 1$ isoforms in birch pollen. BMC Plant Biol. 9:24. doi: 10.1186/1471-2229-9-24

Schenk, M. F., Gilissen, L. J. W. J., Esselink, G. D., and Smulders, M. J. M. (2006). Seven different genes encode a diverse mixture of isoforms of Bet $\mathrm{v}$ 1, the major birch pollen allergen. BMC Genomics 7:168. doi: 10.1186/1471-21 64-7-168

Takeuchi, K., Gyohda, A., Tominaga, M., Kawakatsu, M., Hatakeyama, A., Ishii, N., et al. (2011). RSOsPR10 expression in response to environmental stresses is regulated antagonistically by jasmonate/ethylene and salicylic acid signaling pathways in rice roots. Plant Cell Physiol. 52, 1686-1696. doi: $10.1093 / \mathrm{pcp} / \mathrm{pcr} 105$

van Loon, L. C., Rep, M., and Pieterse, C. M. J. (2006). Significance of inducible defense-related proteins in infected plants. Annu. Rev. Phytopathol. 44, 135162. doi: 10.1146/annurev.phyto.44.070505.143425

Xie, Y.-R., Chen, Z.-Y., Brown, R. L., and Bhatnagar, D. (2010). Expression and functional characterization of two pathogenesis-related protein 10 genes from Zea mays. J. Plant Physiol. 167, 121-130. doi: 10.1016/j.jplph.2009. 07.004

Zobayed, S. M. A., Afreen, F., Goto, E., and Kozai, T. (2006). Plantenvironment interactions: accumulation of hypericin in dark glands of Hypericum perforatum. Ann. Bot. 98, 793-804. doi: 10.1093/aob/ $\operatorname{mcl} 169$

Zubini, P., Zambelli, B., Musiani, F., Ciurli, S., Bertolini, P., and Baraldi, E. (2009). The RNA hydrolysis and the cytokinin binding activities of PR-10 proteins are differently performed by two isoforms of the Pru $\mathrm{p} 1$ peach major allergen and are possibly functionally related. Plant Physiol. 150, 12351247. doi: 10.1104/pp.109.139543

Conflict of Interest Statement: The authors declare that the research was conducted in the absence of any commercial or financial relationships that could be construed as a potential conflict of interest.

Copyright (c) 2016 Karppinen, Derzsó, Jaakola and Hohtola. This is an open-access article distributed under the terms of the Creative Commons Attribution License (CC BY). The use, distribution or reproduction in other forums is permitted, provided the original author(s) or licensor are credited and that the original publication in this journal is cited, in accordance with accepted academic practice. No use, distribution or reproduction is permitted which does not comply with these terms. 